Введение. Установлено, что наличие пневмонии у пациентов с циррозом печени (ЦП) чаще связано с развитием нарушения сознания, почечной недостаточности, септического шока и летального исхода. Так как субфебрильная температура, умеренный лейкоцитоз (или повышение числа лейкоцитов на фроне лейкопении) - частые состояния у пациента с ЦП, следует ожидать нетипичную клиническую картину пневмонии. Пневмония при ЦП может манифестировать классическими признаками декомпенсации цирроза: асцит, печеночная энцефралопатия, варикозное кровотечение.

Цель исследования - ретроспективный анализ частоты и течения пневмонии у пациентов с ЦП, умерших в течение госпитализации.

Материалы и методы. Проанализированы результаты секционных данных 308 пациентов с ЦП, умерших в стационаре. Диагноз ЦП устанавливался на основании данных клиники заболевания и лабораторно-инструментальных методов исследования, при патологоанатомическом исследовании - на основании макрои микроморорологических признаков.

Результаты. Установлено, что пневмонии осложняли течение ЦП у 97 (31,5\% 95\% ДИ 26,3-36,7) умерших в стационаре и являются самым частым видом инфекционного осложнения у данных пациентов. При этом у пациентов с пневмонией, в сравнении с пациентами без пневмонии, чаще обнаруживались сепсис и другие инфекции. Летальный исход наступал в более короткие сроки после госпитализации, чем у пациентов без пневмонии. В ряде случаев (15,5\%; 95\% ДИ 10,2-22,2) верификация пневмонии была существенно затруднена. Чаще это были нозокомиальные варианты заболевания.

Заключение. Спектр возбудителей пневмонии у умерших с ЦП характерен для нозокомиальных инфекционных осложнений и иммунокомпрометированных пациентов.

Ключевые слова: цирроз печени, нозокомиальные инфекции, пневмония.

Для цитирования: Гавриленко, Д. И. Ретроспективный анализ случаев пневмонии у пациентов с циррозом печени / Д. И. Гавриленко, Н. Н. Силивончик, О. А. Жигальцова-Кучинская // Гепатология и Гастроэнтерология. 2019. Т. 3, № 1. С. 43-48. https://doi.org/10.25298/2616-5546-2019-3-1-43-48

\title{
RETROSPECTIVE ANALYSIS OF PNEUMONIA IN CIRRHOTIC PATIENTS
}

\author{
${ }^{1}$ D. Haurylenka, ${ }^{2}$ N. Silivontchik, ${ }^{2} \mathrm{O}$. Zhyhaltsova-Kuchinskaya
}

'State Institution «Republican Research Centre for Radiation Medicine and Human Ecology», Gomel, Belarus

${ }^{2}$ Educational Institution «Belarusian Medical Academy of Post-Graduate Education», Minsk, Belarus

Background. It is established, that pneumonia in patients with cirrhosis is more often associated with the development of impairment of consciousness, renal failure, septic shock and fatal outcome. Since low-grade fever, moderate leukocytosis (or increase of leukocyte count related to leukopenia) are frequent conditions in a patient with cirrhosis, an atypical clinical presentation of pneumonia is likely to be expected. neumonia in cirrhotic patients can be manifested by classic signs of cirrhosis decompensation: ascites, hepatic encephalopathy, variceal bleeding.

The objective of the study is a retrospective analysis of pneumonia incidence and course in cirrhotic patients who died during hospital stay.

Materials and methods. We reviewed 308 autopsies of cirrhotic patients who died in a hospital environment. Cirrhosis was diagnosed using standard criteria (laboratory and instrumental methods, macro- and micromorphological signs).

Results. Pneumonia aggravated cirrhosis in 97 patients (31.5\% of 95\% Cl 26.3-36.7) who died in a hospital environment and is the most common type of infectious complication. Moreover, sepsis and other infections were more common among patients with pneumonia as compared to those without it. A fatal outcome occurred shortly after admission in patients with pneumonia. It was rather difficult to confirm the diagnosis of pneumonia in some cases (15.5\%; 95\% Cl 10.2-22.2). Most often these were nosocomial types of the disease. 
Conclusion. The spectrum of pneumonia pathogens in deceased cirrhotic patients appeared to be characteristic of nosocomial infectious complications and immunocompromised patients.

Keywords: cirrhosis, nosocomial infections, pneumonia

For citation: Haurylenka D, Silivontchik N, Zhyhaltsova-Kuchinskaya O. Retrospective analysis of pneumonia in cirrhotic patients. Hepatology and Gastroenterology. 2019;3(1):43-48. https://doi.org/10.25298/2616-5546-2019-3-1-43-48

\section{Введение}

Бактериальные инфрекции - распространенное и тяжелое осложнение ЦП. При ЦП бактериальные инфекции оказывают ряд негативных (в том числе и специфических) эффректов. Наблюдается усиление печеночной энцефралопатии, гемодинамических нарушений, печеночной дисфункции, увеличивается риск возникновения гепаторенального синдрома (ГРС) и варикозных кровотечений. У пациентов с ЦП имеются разнообразные патологические изменения, предрасполагающие к развитию инфекций, такие как изменения ретикулоэндотелиальной системы, снижение опсонизирующей активности асцитической жидкости (АЖ), дисфункция нейтрофилов. При этом инфекции могут не иметь четких клинических признаков, и как следствие - несвоевременно распознаваться. Более $25 \%$ случаев смерти пациентов с ЦП связаны с развитием бактериальных инфекций. Согласно данным зарубежных исследователей, по частоте обнаружения пневмония среди инфекционных осложнений ЦП занимает 3-е место [1, 2].

Цель исследования - ретроспективный анализ частоты и некоторых особенностей пневмонии у пациентов с ЦП, умерших в течение госпитализации.

\section{Материалы и методы}

В настоящем исследовании проанализированы секционные данные 308 пациентов с ЦП, умерших во время стационарного лечения в лечебных учреждениях г. Гомеля (201 мужчина и 107 женщин) в период с 2000 по 2010 гг. Медиана (Me) возраста на момент смерти обследованных составила 53 года (Min=17 лет, Max=80 лет).

Диагноз ЦП при жизни устанавливался на основании данных клиники заболевания и лабораторно-инструментальных методов исследования, при патологоанатомическом исследовании - на основании макро- и микроморфологических признаков с учетом клинических данных. Степень тяжести ЦП оценивалась по шкале Child-Pugh. Диагноз пневмонии при жизни устанавливался на основании клинической картины болезни, рентгенографии органов грудной клетки и культурального исследования мокроты, на секции - на основании морфологических признаков и результатов микробиологического исследования патологически измененных участков легочной ткани.
Среди умерших пациентов с ЦП преобладали мужчины - 201 (62,3\%), женщин было 107 (34,7\%). Статистически значимых различий по возрасту у мужчин и женщин не выявлено $(\mathrm{t}=-1,216, \mathrm{p}=0,224)$. Лица трудоспособного возраста составили 200 (64,9\%), лица пенсионного возраста - 108 (35,1\%) человек. Медиана длительности пребывания в стационаре составила 7 дней (Min=1 день, Max=49 дней).

Статистическую обработку результатов выполняли с помощью программы Statistica 6.0. Peзультаты обработаны с помощью непараметрической статистики. Для сравнительного анализа симметричных вариационных рядов использовался критерий Стьюдента (t). Описательная статистика представлена минимальным (Min) и максимальным (Мах) значениями, медианой $(\mathrm{Me})$. Изучение частоты признаков проводилось с использованием 95\% доверительных интервалов (95\% ДИ), а их сравнение - на основании критерия $\mathrm{X}^{2}$. За критический уровень статистической значимости принимали вероятность безошибочного прогноза, равную 95\% $(p<0,05)$.

\section{Результаты и обсуждение}

В результате патологоанатомического исследования 308 умерших с ЦП инфекционные осложнения выявлены в 129 случаях (41,9\%; 95\% ДИ 36,4-47,4\%), что соответствует данным большинства исследователей проблемы [1-4]. Характеристика видов инфекционных осложнений и частота их выявления представлена в таблице 1.

Таблица 1. - Структура инфекционных осложнений у пациентов с циррозом печени

\begin{tabular}{|l|c|c|}
\hline \multirow{2}{*}{$\begin{array}{l}\text { Инфоекционные } \\
\text { осложнения }\end{array}$} & $\begin{array}{c}\text { Число } \\
\text { инфекционных } \\
\text { осложнений }\end{array}$ & \begin{tabular}{c} 
Доля в общей группе умер- \\
ших пациентов с циррозом \\
\cline { 2 - 2 } печени (n=308), \%; 95\% Ди
\end{tabular} \\
\hline $\begin{array}{l}\text { Спонтанный } \\
\text { бактериальный } \\
\text { перитонит }\end{array}$ & 8 & $2,6(0,8-4,4)$ \\
\hline Пневмония & 97 & $31,5(26,3-36,7)$ \\
\hline Пиелонесрит & 27 & $8,8(5,6-11,9)$ \\
\hline Сепсис & 13 & $4,2(1,9-6,5)$ \\
\hline $\begin{array}{l}\text { Рожистое } \\
\text { воспаление }\end{array}$ & 3 & 0,97 \\
\hline Прочие & 38 & $11,7(8,1-15,3)$ \\
\hline
\end{tabular}

Приведенные в таблице данные свидетельствуют о том, что пневмония является наиболее частым инфекционным осложнением у умерших с ЦП - 97 случаев (31,5\% 95\% ДИ 26,3-36,7). 
Другими нередкими инфекциями были традиционные для ЦП пиелонефрит, сепсис, спонтанный бактериальный перитонит [1-5].

Для реализации целей работы из общего числа пациентов выделена группа пациентов с ЦП с установленной пневмонией $(n=97)$ и проведен сравнительный анализ ее с группой пациентов с ЦП без пневмонии $(\mathrm{n}=211)$.

При сопоставлении секционных и клинических данных оказалось, что совпадение патологоанатомического и клинического диагноза пневмонии имело место в 73 случаях из 97 (75,3\%; 95\% ДИ 65,5-83,5). У 24 пациентов с ЦП пневмония при жизни не была распознана $(24,7 \%$; 95\% ДИ 16,5-34,5). Вместе с тем из числа 154 случаев пневмоний, установленных при жизни, в 82 (53,3\%; 95\%ДИ 45,1-61,3) не получено морфологического подтверждения данного диагноза (по данным секционного исследования). Следовательно, у 26,6\% (95\% ДИ 21,8-31,9) пациентов с ЦП, умерших в стационаре, имела место прижизненная гипердиагностика пневмонии.

Таблица 2. - Этиология цирроза печени у пациентов с циррозом печени с установленной пневмонией и без пневмонии

\begin{tabular}{|c|c|c|c|c|c|c|}
\hline \multirow[t]{2}{*}{$\begin{array}{c}\text { Этиология } \\
\text { цирроза печени }\end{array}$} & \multicolumn{2}{|c|}{$\begin{array}{c}\text { Пациенты с } \\
\text { пневмонией } \\
(n=97)\end{array}$} & \multicolumn{2}{|c|}{$\begin{array}{c}\text { Пациенты без } \\
\text { пневмонии } \\
(n=211)\end{array}$} & \multirow[t]{2}{*}{$x^{2}$} & \multirow[t]{2}{*}{$p$} \\
\hline & $n$ & $\%$ & $n$ & $\%$ & & \\
\hline Алкогольный & 62 & 63,93 & 130 & 61,61 & 0,150 & 0,698 \\
\hline Вирусный & 4 & 4,12 & 7 & 3,32 & 0,130 & 0,723 \\
\hline Смешанный & 4 & 4,12 & 10 & 4,74 & 0,060 & 0,809 \\
\hline Билиарный & 4 & 4,12 & 0 & 0 & 8,820 & 0,003 \\
\hline $\begin{array}{l}\text { Лекарственноиндуцированный } \\
\text { (НПВП) }\end{array}$ & 0 & 0 & 1 & 0,47 & 0,460 & 0,497 \\
\hline Неуточненный & 23 & 23,71 & 63 & 29,86 & 0,530 & 0,466 \\
\hline
\end{tabular}

В таблице 2 представлены данные об особенностях этиологии ЦП у пациентов селективных групп.

Данные, приведенные в таблице, свидетельствуют о том, что в основном в сравниваемых группах этиология ЦП была идентичной, за одним исключением: у всех умерших с билиарным ЦП были диагностированы пневмонии $\left(x^{2}=8,820\right.$, $\mathrm{p}=0,003)$.

Далее был проведен сравнительный анализ некоторых клинических параметров в группах умерших с ЦП с пневмонией и без пневмонии (табл. 3).

Пациенты сравниваемых групп были однородны по возрасту ( $\mathrm{t}=-0,958, p=0,338$ ), полу $\left(x^{2}=1,470, p=0,226\right)$, по тяжести ЦП $\left(x^{2}=0,050\right.$, $p=0,827)$ и наличию таких проявлений портальной гипертензии, как асцит $\left(X^{2}=0,010, p=0,934\right)$ и печеночный гидроторакс $\left(X^{2}=0,180, p=0,674\right)$. У пациентов с ЦП с установленной пневмонией хирургические вмешательства выполнялись достоверно чаще $\left(X^{2}=17,180, p<0,001\right)$. Причиной их стали разные варианты нагноительных заболеваний (в таблице 1 они внесены в графу «прочие»). В связи с этим представляется интересным аналитическое сопоставление сравниваемых групп по частоте и характеру выявляемых у них других (кроме пневмоний) инфекционных осложнений (табл. 4).

В группе пациентов с установленной пневмонией другие инфекционные осложнения имелись или развивались достоверно чаще $\left(X^{2}=31,210\right.$, $\mathrm{p}<0,001)$, в первую очередь это сепсис $\left(X^{2}=17,750, p<0,001\right)$, а среди прочих - абсцесс легкого $\left(X^{2}=4,380\right.$, $\mathrm{p}=0,036)$ и поддиафрагмальный абсцесс $\left(x^{2}=4,380, p=0,036\right)$.

Таблица 3. - Сравнительная характеристика клинических параметров пациентов с пневмонией и без данного заболевания

\begin{tabular}{|c|c|c|c|c|c|c|c|}
\hline \multirow[t]{2}{*}{ Параметры } & \multicolumn{3}{|c|}{$\begin{array}{c}\text { Пациенты с пневмонией } \\
(\mathrm{n}=97)\end{array}$} & \multicolumn{3}{|c|}{$\begin{array}{l}\text { Пациенты без пневмонии } \\
(\mathrm{n}=211)\end{array}$} & \multirow{2}{*}{$t / x^{2}(p)$} \\
\hline & $\mathrm{n}$ & $\%$ & $\mathrm{M} \pm \sigma$ & $\mathrm{n}$ & $\%$ & $\mathrm{M} \pm \sigma$ & \\
\hline Возраст & 97 & 100 & $52,95 \pm 11,40$ & 211 & 100 & $51,62 \pm 11,36$ & $-0,958(0,338)$ \\
\hline $\begin{array}{l}\text { Пол } \\
\text { мужчины } \\
\text { женщины }\end{array}$ & $\begin{array}{l}68 \\
29 \\
\end{array}$ & $\begin{array}{l}70,1 \\
29,9\end{array}$ & $\begin{array}{l}52,13 \pm 11,37 \\
54,89 \pm 11,43\end{array}$ & $\begin{array}{c}133 \\
78\end{array}$ & $\begin{array}{l}63,0 \\
37,0\end{array}$ & $\begin{array}{l}51,12 \pm 11,93 \\
52,46 \pm 10,34\end{array}$ & $1,470(0,226)$ \\
\hline Асцит & 46 & 47,4 & & 99 & 46,9 & & $0,010(0,934)$ \\
\hline Печеночный гидроторакс & 24 & 24,7 & & 57 & 27,1 & & $0,180(0,674)$ \\
\hline $\begin{array}{l}\text { Класс тяжести по Child-Pugh: } \\
\text { В } \\
\text { С }\end{array}$ & $\begin{array}{l}18 \\
79 \\
\end{array}$ & $\begin{array}{l}18,6 \\
81,4\end{array}$ & & $\begin{array}{c}37 \\
174 \\
\end{array}$ & $\begin{array}{l}17,5 \\
82,5\end{array}$ & & $0,050(0,827)$ \\
\hline Варикозные вены пищевода и/или желудка & 67 & 69,1 & & 183 & 86,7 & & $13,560(<0,001)$ \\
\hline $\begin{array}{l}\text { Кровотечение из варикозных вен пищевода и/или } \\
\text { желудка }\end{array}$ & 29 & 29,9 & & 106 & 50,2 & & $11,170(<0,001)$ \\
\hline Хирургические вмешательства & 19 & 19,6 & & 10 & 4,7 & & $17,180(<0,001)$ \\
\hline Длительность пребывания в стационаре & 97 & 100 & $8,30 \pm 8,94$ & 211 & 100 & $11,14 \pm 9,14$ & $-2,566(0,010)$ \\
\hline
\end{tabular}


Далее в группе пациентов с установленной на секции пневмонией был проведен анализ некоторых клинических и эпидемиологических особенностей пневмонии. Обнаружено, что в 57 случаях $(58,8 \%)$ пневмонии развивались спустя 72 ч после госпитализации, т. е. были госпитальными (нозокомиальными), и в 40 случаях $(41,2 \%)$ установлен диагноз внебольничной пневмонии. Пневмонии, не диагностированные во время госпитального наблюдения, были преимущественно нозокомиальными $-79,2 \%\left(x^{2}=5,480, p=0,019\right)$ и достоверно чаще сочетались с печеночным гидротораксом $\left(X^{2}=4,210, p=0,040\right)$, который маскирует проявления болезни [6-8].

В большинстве случаев пневмония имела двусторонний характер - 68 пациентов $(70,1 \%)$, с преимущественным вовлечением в патологический процесс нижних долей легких - 80 случаев

Таблица 4. - Сравнительная характеристика инфекционных осложнений у пациентов с ЦП с пневмонией и без данного заболевания

\begin{tabular}{|c|c|c|c|c|c|c|}
\hline \multirow[t]{2}{*}{$\begin{array}{c}\text { Инфрекционные } \\
\text { осложнения }\end{array}$} & \multicolumn{2}{|c|}{$\begin{array}{c}\text { Пациенты } \\
\text { с пневмонией } \\
(\mathrm{n}=97)\end{array}$} & \multicolumn{2}{|c|}{$\begin{array}{c}\text { Пациенты } \\
\text { без } \\
\text { пневмонии } \\
(\mathrm{n}=211)\end{array}$} & \multirow{2}{*}{\multicolumn{2}{|c|}{$X^{2}(p)$}} \\
\hline & абс. & $\%$ & абс. & $\%$ & & \\
\hline $\begin{array}{l}\text { Спонтанный бактериальный } \\
\text { перитонит }\end{array}$ & 2 & 2,1 & 6 & 2,8 & 0,160 & 0,688 \\
\hline Пиелонефрит & 12 & 12,4 & 15 & 7,1 & 2,300 & 0,129 \\
\hline Сепсис & 11 & 11,3 & 2 & 0,9 & 17,750 & $<0,001$ \\
\hline Рожистое воспаление & 1 & 1,0 & 2 & 0,9 & 0,000 & 0,945 \\
\hline Прочие, в т.ч.: & 23 & 23,7 & 15 & 7,1 & 16,940 & $<0,001$ \\
\hline менингит & 3 & & 1 & & 3,560 & 0,059 \\
\hline туберкулез & - & & 3 & & 1,390 & 0,238 \\
\hline абсцесс легкого & 2 & & - & & 4,380 & 0,036 \\
\hline $\begin{array}{l}\text { абсцесс поджелудочной } \\
\text { железы }\end{array}$ & 2 & & 1 & & 1,740 & 0,187 \\
\hline абсцесс правой доли печени & - & & 1 & & 0,460 & 0,497 \\
\hline поддиафрагмальный абсцесс & 2 & & - & & 4,380 & 0,036 \\
\hline подпеченочный абсцесс & 1 & & - & & \multirow{5}{*}{2,180} & \multirow{5}{*}{0,139} \\
\hline перивезикальный абсцесс & 1 & & - & & & \\
\hline карбункул почки & 1 & & - & & & \\
\hline флегмонозный тифлит & 1 & & - & & & \\
\hline паратонзиллярный абсцесс & 1 & & - & & & \\
\hline паранефральный абсцесс & - & & 1 & & \multirow{2}{*}{0,460} & \multirow{2}{*}{0,497} \\
\hline фллегмона бедра & - & & 1 & & & \\
\hline $\begin{array}{l}\text { флегмона паранефррального } \\
\text { пространства }\end{array}$ & 1 & & - & & \multirow[t]{2}{*}{2,180} & \multirow[t]{2}{*}{0,139} \\
\hline острый гнойный полисинусит & 1 & & - & & & \\
\hline актиномикоз кожи & - & & 1 & & \multirow{2}{*}{0,460} & \multirow{2}{*}{0,497} \\
\hline остеомиелит & - & & 1 & & & \\
\hline пролежень & 1 & & 1 & & 0,320 & 0,571 \\
\hline вторичный перитонит & 3 & & 4 & & 0,430 & 0,512 \\
\hline флегмона дна полости рта & 1 & & - & & \multirow{3}{*}{2,180} & \multirow{3}{*}{0,139} \\
\hline диафрагмит & 1 & & - & & & \\
\hline яерикардит & 1 & & - & & & \\
\hline
\end{tabular}

(85,5\%). Долевая пневмония выявлена у 20 пациентов $(20,36 \%)$, из них у 6 обнаружено тотальное или субтотальное поражение легких. Среди умерших со столь массивной воспалительной инсильтрацией легочной ткани было 5 мужчин, 4 из которых страдали алкогольным ЦП; во всех этих эпизодах пневмония диагностирована при жизни. Гораздо чаще - 77 случаев $(79,4 \%)$ - в патологический процесс вовлекались один или несколько сегментов, или долька легочной ткани, т. е. имела место очаговая пневмония.

Этиологические факторы пневмонии идентифрицированы в 28 (9,1\%) случаях (табл. 5).

Как следует из представленных данных, среди случаев пневмонии с установленной этиологией наиболее частыми возбудителями в виде монокультуры и в ассоциации были грамотрицательные бактерии - на их долю приходилось $75 \%$ от общего числа выделенных штаммов (21 из 28 случаев). Среди грамотрицательных микроорганизмов преобладали представители семейства Enterobacteriaceae как в монокультуре $(n=7)$, так и в ассоциациях с грибами $(\mathrm{n}=7)$ и кокковой фрлорой $(\mathrm{n}=3)$. Грамположительные кокки обнаружены в четырех (14\%) из 28 случаев. Грибковая фрлора выявлена в десяти случаях (36\%): в двух рода Candida, в одном - рода Aspergillus, кроме того, в семи случаях - Candida sp. в ассоциации с представителями грамотрицательной фрлоры.

Всего ассоциации микроорганизмов выделены в 13 случаях (46\%), из них в 12 - двух (преимущественно представителей грамотрицательной микрофрлоры и грибов рода Candida), а в одном - четырех микроорганизмов (Pseudomonas aeruginosa + Proteus vulgaris + Escherichia coli + Staphylococcus aureus).

Случаи сочетания пневмонии с сепсисом и другими тяжелыми инфекционными осложнениями были связаны с обнаружением грамотрицательной фрлоры в виде монокультуры, а также в ассоциации с грибами рода Candida.

Сроки пребывания в стационаре на момент обнаружения указанных инфекционных осложнений, спектр обнаруженных возбудителей и их ассоциации могут указывать на нозокомиаль- 
Таблица 5. - Результаты микробиологического исследования ткани легкого и некоторые клинические характеристики умерших в стационаре пациентов с циррозом печени

\begin{tabular}{|c|c|c|c|}
\hline Микрофлора & $n$ & $\begin{array}{c}\text { Сроки } \\
\text { пребывания } \\
\text { в стациона- } \\
\text { ре, сут. }\end{array}$ & $\begin{array}{c}\text { Другие } \\
\text { инфекционные } \\
\text { осложнения }\end{array}$ \\
\hline Грамотрицательная фллора & 9 & & \\
\hline Enterobacteriaceae & 7 & - & - \\
\hline Proteus mirabilis & 1 & 12 & Сепсис \\
\hline Klebsiella pneumonia & 2 & $\begin{array}{c}43 \\
4\end{array}$ & $\begin{array}{l}\text { Сепсис } \\
\text { Сепсис }\end{array}$ \\
\hline Escherichia coli & 2 & $\begin{array}{c}13 \\
8\end{array}$ & $\begin{array}{l}\text { Нет } \\
\text { Нет }\end{array}$ \\
\hline Enterobacter sp. & 2 & $\begin{array}{c}35 \\
8\end{array}$ & $\begin{array}{l}\text { Нет } \\
\text { Нет }\end{array}$ \\
\hline Pseudomonadaceae & 2 & - & - \\
\hline Pseudomonas aeruginosa & & $\begin{array}{c}1 \\
15\end{array}$ & $\begin{array}{c}\text { Нет } \\
\text { Пиелонефрит + } \\
\text { паратонзиллярный } \\
\text { абсцесс }\end{array}$ \\
\hline $\begin{array}{l}\text { Грамположительная флора, } \\
\text { в т.ч. в ассоциации }\end{array}$ & 4 & & \\
\hline Staphylococcus aureus & 1 & 1 & Перикардит \\
\hline Staphylococcus epidermidis & 1 & 6 & Нет \\
\hline Streptococcus sp. & 1 & 3 & Нет \\
\hline $\begin{array}{l}\text { Staphylococcus aureus+Enterococcus } \\
\text { faecalis }\end{array}$ & 1 & 2 & Нет \\
\hline $\begin{array}{l}\text { Микробные ассоциации грамотрицатель- } \\
\text { ных и грамположительных бактерий }\end{array}$ & 4 & & \\
\hline Escherichia coli+Staphylococcus epidermidis & 2 & $\begin{array}{l}1 \\
4\end{array}$ & $\begin{array}{c}\text { Нет } \\
\text { Вторичный } \\
\text { перитонит }\end{array}$ \\
\hline Enterobacter $\mathrm{sp} .+$ Enterococcus faecalis & 1 & 2 & $\begin{array}{c}\text { Рожистое } \\
\text { воспаление }\end{array}$ \\
\hline $\begin{array}{l}\text { Pseudomonas aeruginosa+Staphylococcus } \\
\text { aureus }\end{array}$ & 1 & 2 & Нет \\
\hline Грибы & 3 & & \\
\hline Aspergillum & 1 & 30 & $\begin{array}{c}\text { Перивезикальный } \\
\text { абсцесс }\end{array}$ \\
\hline Candida sp. & 2 & $\begin{array}{l}34 \\
38\end{array}$ & $\begin{array}{c}\text { Абсцесс тела } \\
\text { поджелудочной } \\
\text { железы } \\
\text { Сепсис }\end{array}$ \\
\hline $\begin{array}{l}\text { Микробные ассоциации г } \\
\text { рамотрицательных бактерий с грибами }\end{array}$ & 7 & & \\
\hline Escherichia coli+Candida sp. & 5 & $\begin{array}{c}11 \\
17 \\
19 \\
12 \\
7\end{array}$ & $\begin{array}{c}\text { Пиелонефрит } \\
\text { Пиелонефрит } \\
\text { Сепсис } \\
\text { Нет } \\
\text { Нет }\end{array}$ \\
\hline Klebsiella pneumoniae + Candida sp. & 2 & $\begin{array}{c}7 \\
16\end{array}$ & $\begin{array}{c}\text { Нет } \\
\text { Сепсис + } \\
\text { пиелонефрит }\end{array}$ \\
\hline Другие микробные ассоциации & 1 & & \\
\hline $\begin{array}{l}\text { Pseudomonas aeruginosa+Proteus vulgari- } \\
\text { s+Escherichia coli+Staphylococcus aureus }\end{array}$ & & 18 & $\begin{array}{c}\text { Вторичный пери- } \\
\text { тонит }\end{array}$ \\
\hline
\end{tabular}

ный характер большинства случаев пневмоний. Наличие грибов рода Candida в гистологическом материале умерших пациентов свидетельствовало об инвазивном кандидозе. По данным исследования аутопсийного материала, среди установленных возбудителей пневмонии преобладали характерные для нозокомиальной инфекции. Нозокомиальный характер пневмоний с установленной этиологией у некоторых пациентов подтверждается сроками установления данного инфекционного осложнения при патологоанатомическом исследовании. В то же время инфекции, развившиеся через 48 часов после поступления в стационар, хотя и относятся по определению к нозокомиальным, но по существу могут быть отражением активации эндогенной микробной флоры пациентов с ЦП. Выявлялась грибковая флора, что встречается при иммунодефриците и длительном использовании антибиотиков.

Учитывая данные микробиологического исследования мокроты и ткани легкого, а также известный фракт наличия иммунной дисфункции у пациентов с декомпенсированным ЦП [9], можно сделать предположение о доминирующей роли условно-патогенной грибковой флоры в развитии пневмонии у пациентов с декомпенсированным ЦП, умерших в стационаре.

\section{Выводы}

1. Пневмония - наиболее частое инфекционное осложнение у умерших в стационаре пациентов с ЦП (31,5\%; 95\%ДИ 26,3-37,0).

2. Неустановленная при жизни пневмония достоверно чаще имела характер нозокомиальной инфекции $\left(X^{2}=5,480, p=0,019\right)$ и чаще сочеталась $\mathrm{c}$ печеночным гидротораксом $\left(x^{2}=4,210, p=0,040\right)$.

3. Среди установленных возбудителей пневмонии преобладали штаммы (семейство Enterobacteriaceae, Candida sp.), характерные для нозокомиальной инфекции, а также для иммунодефицитных состояний.

4. Выявление грибковой фрлоры в качестве причины пневмонии в $36 \%$ случаев демонстрирует необходимость микробиологического мониторинга и учета данной группы возбудителей для последующей коррекции этиотропной терапии. 


\section{References}

1. Tandon P, Garcia-Tsao G. Bacterial infections, sepsis, and multiorgan failure in cirrhosis. Semin. Liver Dis 2008:28(1):26-42. doi: 10.1055/s-2008-1040319.

2. Merli M, Lucidi C, Giannelli V, Giusto M, Riggio O, Falcone M, Ridola L, Attili AF. Cirrhotic patients are at risk for health care-associated bacterial infections. Clin. Gastroenterol. Hepatol. 2010;8(11):979-985. doi: 10.1016/j. cgh.2010.06.024

3. Wong F. Acute kidney injury in liver cirrhosis: new definition and application. Clin. Mol. Hepatol. 2016;22(4):415-422. doi: 10.3350/cmh.2016.0056.

4. Garcia-Tsao G. Current Management of the Complications of Cirrhosis and Portal Hypertension: Variceal Hemorrhage Ascites, and Spontaneous Bacterial Peritonitis. Dig. Dis. 2016;34(4):382-386. doi: 10.1159/000444551.

5. Kim HJ, Lee HW. Important predictor of mortality in patients with end-stage liver disease. Clin. Mol. Hepatol. 2013;19(2):105-115. doi: 10.3350/cmh.2013.19.2.105.

6. Falguera $\mathrm{M}$, Trujillano $\mathrm{J}$, Caro $\mathrm{S}$, Menéndez $\mathrm{R}$, Carratalà $J$, Ruiz-González A, Vilà M, García M, Porcel JM, Torres A; NAC-CALIDAD. A prediction rule for estimating the risk of bacteremia in patients with community-acquired pneumonia. Clin. Infect. Dis. 2009;49(3):409-416. doi: 10.1086/600291.

7. Kim YK, Kim Y, Shim SS. Thoracic complications of liver cirrhosis: radiologic findings. Radiographics. 2009;29(3):825-837. doi: 10.1148/rg.293085093.

8. Cardenas A, Arroyo V. Management of ascites and hepatic hydrothorax. Best Pract. Res. Clin. Gastroenterol. 2007;21(1):55-75. doi: 10.1016/j.bpg.2006.07.012.

9. Bonnel AR, Bunchorntavakul C, Reddy KR. Immune dysfunction and infections in patients with cirrhosis. Clin Gastroenterol. Hepatol. 2011;9(9):727-738. doi: 10.1016/j. cgh.2011.02.031.

Поступила: 28.03.2019

Принята к печати: 02.05.2019

\section{Viral Hepatitis: Acute Hepatitis}

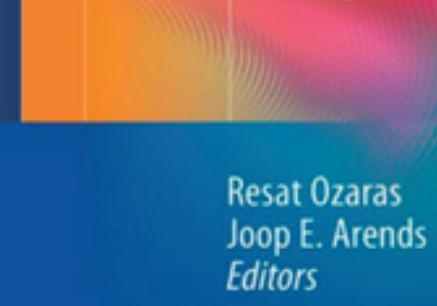

$\underline{\underline{\underline{D}} \text { Springer }}$
Viral Hepatitis: Acute Hepatitis Paperback / ed: R. Ozaras, J. E. Arends. - Cham : Springer, 2019. - 120 p. ISBN 978-3030035341.

This book presents up-to-date, practically oriented information on major topics in acute hepatitis virus infections. The coverage encompasses epidemiology, diagnosis (including molecular methods), treatment and clinical challenges. In addition, it deals with the epidemiology and management of vir hepatic infections in HIV co-infected patients. The book opens by examining the local and global epidemiology of acute hepatic infections. Detailed attention is then paid to the acute hepatic viruses $A, B, C$ and $E$. Acute Hepatitis will be of high value for general practitioners and specialists in gastroenterology, infectious diseases, and internal medicine. It will be international in scope in terms of both authorship and appeal. 